\title{
A Developmental English Proficiency Test (ADEPT): A Study In The Effectiveness Of The ADEPT Assessment On Teacher Candidate Instructional Planning For English Language Learners
}

\author{
Nancy Myers, Director for the California Reading and Literature Project, USA
}

Janice Tucker, California Lutheran University, USA

\begin{abstract}
English Language Learners (ELLS) are a dynamic and rapidly growing population within the California school system. In this age of greater accountability, teachers need access to the tools necessary for effectively reaching this growing subpopulation of students. In this study, A Developmental English Proficiency Test (ADEPT), a language assessment tool, is examined with regards to its effectiveness in assisting teacher candidates in their instructional planning for ELLs. Results from qualitative and quantitative data show that the ADEPT was effective in helping teacher candidates to plan and differentiate instruction for ELLs. Additionally, the ADEPT provided concrete data to report to school administrators and parents on students' progress.
\end{abstract}

Keywords: English Language Learners; ADEPT; California Reading and Literature Project; Assessment; CRLP; Accountability; Differentiation; Instructional Planning

\section{INTRODUCTION}

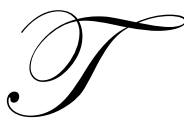

he California Reading and Literature Project (CRLP) is one of nine California Subject Matter Projects working in California and is governed through the University of California's Office of the President. CRLP is a program that provides professional development for K-12 teachers to facilitate the development of student literacy and support English Language Learners (ELLs). One of the goals of the CRLP is to create a bridge between the academic world of the university and the world of the classroom and its students. This relationship allows teachers to develop and improve their teaching practices and improve their students' achievement by concretely linking the theory and research of the academic world to their classrooms.

The ADEPT assesses a student's ability to understand and generate English language conventions according to the levels of English Proficiency. The ADEPT 2006 adaptation that is currently in use has undergone validity and reliability studies through the University of California, Santa Cruz, and was found to be a valid and reliable assessment instrument, aligned with the California English Language Development Test (CELDT).

The ADEPT assessment was designed to assist teachers in effectively and efficiently planning and delivering their instruction to meet the needs of students at varying levels of English language proficiency. This research study has been designed to further examine teacher knowledge of effective teaching practices gained as a result of the ADEPT assessor certification training.

Use of the ADEPT assessment is required for the reading methods course's culminating assignment. Teacher candidates use the ADEPT assessment to identify ELL students' strengths and needs, to help them plan 
instructional activities, and to describe how these instructional activities meet standards and help students succeed. This training is typically given to teachers and other paraprofessionals working with students full time. This study has been designed to examine the impact of this training on pre-service teacher knowledge and practices.

\section{LITERATURE REVIEW}

The focus on ELLs in research has increased over the years in large part due to the increase in ELLs' impact on the educational system. Gándara, Rumberger, Maxwell-Jolly, and Callahan (2003) report,

The fact that the United States remains an immigrant nation is nowhere more apparent than in our public schools where an increasing percentage of students are English learners. In 2000-01 these students represented ten percent of all students in the United States, and 25 percent of California's public school population. (p. 2 )

Ventura County, where California Lutheran University (CLU) is located, is no exception to this trend. In 2008-2009, ELLs accounted for 40\% of kindergarten students and 23\% of total student enrollment for Ventura County's K-12 schools (Ed Data, 2010). The following graph (Figure 1) represents the total number of ELLs in Ventura County and depicts a steady growth in that population from 1995-2010. Ventura County has been selected as the example for this literature review because this research study will take place in Ventura County.

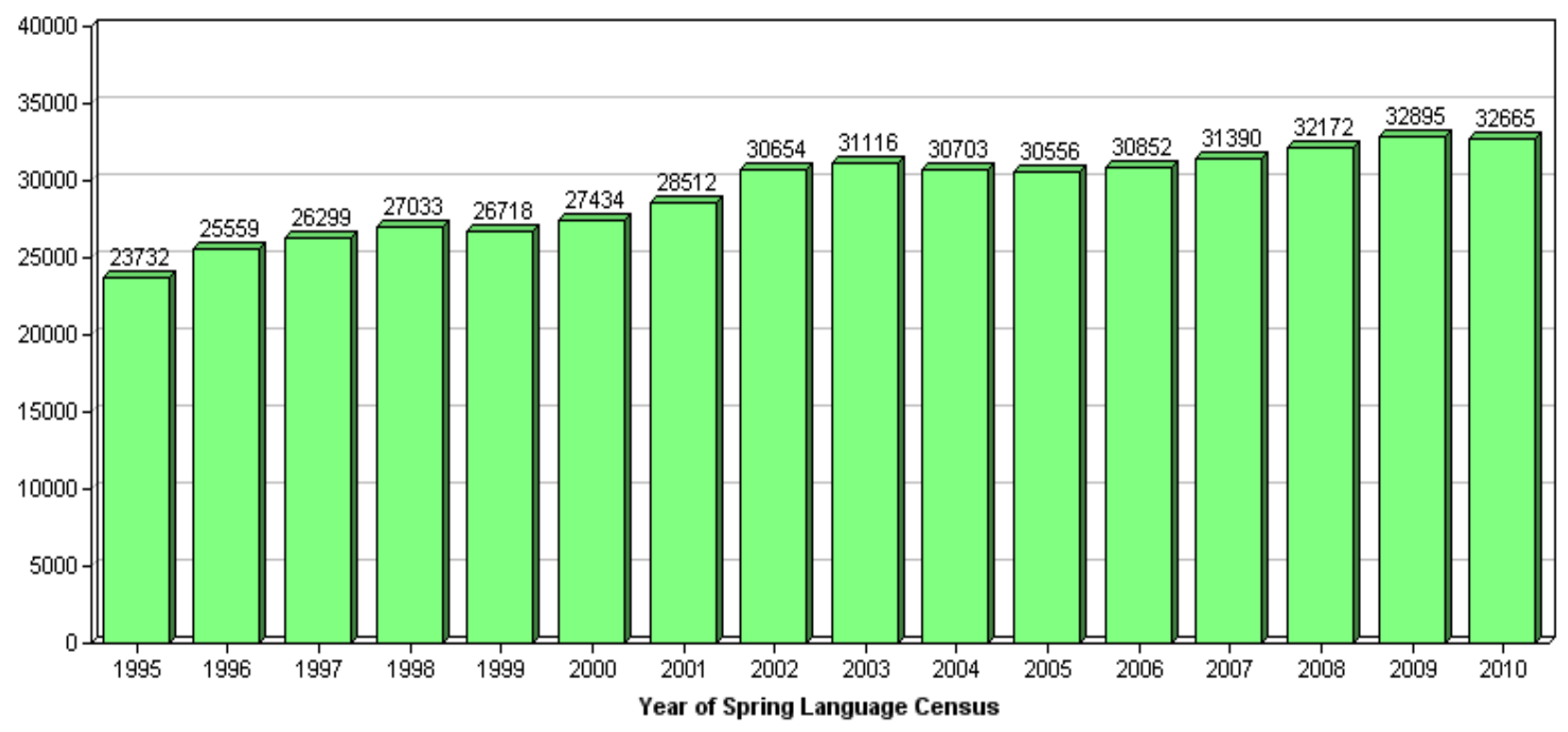

Figure 1. Number of English Learners for Ventura County (California Department of Education, 2010)

Unfortunately, the statistics about ELLs do not end with their population growth. Gándara, et al. (2003) report, "A persistent gap in test scores is a major factor in the school experience of English learners. As a group they continue to perform more poorly than English-speaking students throughout their entire school career" (p. 4). In 2009, of the 21 school districts in Ventura County, 14 did not meet the Adequate Yearly Progress goals for ELLs in English Language Arts (California Department of Education, 2009).

Indeed, the increase in population of ELLs has required teachers to evaluate their teaching practices and explore new methods in reaching this population of students. In addition, ELLs typically account for the lowest test scores and often have the most difficult time succeeding academically. Thus, increased pressure from local authorities to raise test scores for the ELL population has also provided the impetus for reform. The purpose of this literature review is to examine the significance of best practices for teaching ELLs and provide justification for the 
use of the ADEPT assessment as a helpful tool in lesson planning geared to meet the specific needs of ELLs in the classroom.

Research shows that finding the best practices to meet the needs of ELLs is a multifaceted issue. Current literature suggests that it can take up to 3 to 5 years for ELLs to gain oral proficiency in English, and up to 4 to 7 years to gain academic English proficiency (Hakuta, 2000). These statistics are true even for districts where instruction for ELLs is considered "successful." Kenji Hakuta's research on the development of English proficiency among ELLs suggests that established policy that includes short term rigorous instruction with yearly assessment may not be adequate to meet the needs of ELLs. Therefore, there must be a paradigm shift in educating these unique learners.

Researcher James Cummins (1995) has advocated for a paradigm shift in the educational system's response to ELLs. Cummins argues that there must be significant change in personal and community attitude toward ELLs, and moreover, that individual teachers must become advocates for ELLs' linguistic talents and work toward a framework that encourages student independence. Educators must not use new policies and programs to replace dayto-day interaction and intervention with ELLs. Interventions must be based upon the individual needs of each student in order to be most effective in addressing areas of need and promoting areas of strength.

Building upon the research of both Hakuta (2000) and Cummins (1995), Garcia and Beltran (2005) propose the theory that "most successful projects are successful because they are planned" (p. 197). Similarly, instruction is successful when it is planned to meet the specific needs of the variety of students in the classroom. This is especially true of ELLs where instruction must be carefully planned to meet their needs within time, content, and policy constraints. Recognition of the linguistic differences between ELLs and native speakers is key, and understanding the timeline of language acquisition assists teachers in preparing appropriate instruction.

Similarly, researchers Ruddell and Unrau (1997) state that educators must be responsive and reflective in order to be effective. Influential teachers show excitement and care for students, differentiate instruction based on student ability and motivation, engage students in a process of intellectual discovery, and help students to understand problems. Students note these characteristics in teachers whether the students are high achieving or low achieving. Influential teachers are always striving to redesign their instructional program to meet the diverse needs of the students in their classroom. Teachers must reflect on the development of self, instructional orientation, and task engagement resources. Although not explicitly mentioned, this research has clear implications for how a teacher must relate to ELLs in meeting the diverse needs of their classroom.

As a part of the paradigm shift for teaching ELLs, Gonzalez and Darling-Hammond (1997) argue that professional development must be reconsidered in light of the demographic changes in American classrooms. Gonzalez and Darling-Hammond assert that professional development related to teaching ELLs should begin in preservice teaching, in beginning teaching, and throughout the rest of a teacher's career. Support must be given to new teachers to facilitate understanding of the ELLs in their classrooms and prepare them to work collaboratively with other staff members to strategize.

Widening the scope of Gonzalez and Darling-Hammond's (1997) findings to pre-service teachers and any other individual involved in the education of students, Grant and Wong (2003) advocate for educators, pre-service teachers, and paraprofessionals to be actively engaged in developing best practices for reaching ELLs. This means that emphasis must be placed at all stages of teacher education in supporting the development of consciousness about the challenges ELLs face and to close the achievement gap between native speakers and ELLs. The authors argue that reading specialists and teachers must shift to a paradigm where "the belief that academic success for language minority learners can be achieved through culturally inclusive theoretical frameworks for research methods and literacy assessment as well as literacy instruction" (p. 389).

Recent research from Lucas, Villegas, and Freedson-Gonzalez (2008) supports the idea that pre-service teachers must receive education in best practices for ELLs during their higher education preparation for the classroom. More experienced teachers have struggled as a result of a lack of preparation for this new population in their classrooms. Lucas et al. assert that "through professional development, we can learn about resources to which 
we can direct future teachers for information on teaching ELLs, and perhaps most important, we can develop our understandings about the education of ELLs" (p. 371).

A final, significant point has been made by Laurie Olson (2010) in a recent and groundbreaking research and policy report regarding the classification of long term ELLs. Olson estimates that there are more than 330,000 California students in grades 6-12 who are classified as Long Term English Learners, struggling academically, with little or no progress toward English proficiency. As many other researchers have noted, Olson states that many ELLs become stuck at the intermediate level and continue through the educational system without receiving the extra academic assistance necessary to progress to a higher level of English proficiency. This group of ELLs functions well socially and speaks with confidence despite lacking the necessary academic language to be successful in school. Olson's report reminds educators of the legal mandate in California that

English learners cannot be permitted to incur irreparable academic deficits during the time in which they are mastering English... School districts are obligated to address deficits as soon as possible, and to ensure that their schooling does not become a permanent dead end. (p. 3)

Such students' progress must be monitored beginning in elementary school so that special language services can be offered earlier and more effectively, thus improving achievement in secondary schooling.

The current research on best practices for teaching ELLs is extensive, but not conclusive. ELLs are a complex and growing population that requires special attention within the classroom. Research points to the need for specific education of teachers, pre-service teachers, and paraprofessionals in meeting the needs of ELLs. Although no one method for providing this information to educators has been suggested, growing research supports the notion that more professional development is needed, and that professional development is more useful the earlier it is received in an educator's career. The ELL population in the classroom must be reached to prevent more and more children from receiving the label of "Long Term English Learner." Every student should have an equal opportunity to succeed and receive the educational resources necessary to meet this goal.

\section{OBJECTIVE, RESEARCH DESIGN AND PROCEDURE}

The ADEPT assessment is a promising tool for teachers of ELLs to pinpoint their students' instructional needs. By regularly assessing students, teachers are able to determine at what language proficiency level students are functioning and plan lessons accordingly. This knowledge boosts the confidence of teachers trying to meet the needs of their ELLs. This is an especially useful tool for pre-service teacher candidates who often do not know where to begin with instruction for ELLs.

The purpose of this study is to determine the effect of the ADEPT assessment training on teacher knowledge of effective teaching practices for ELLs. This study took place from October 2009 to May 2010.

Volunteers from the cohort of teacher candidates from CLU's teacher preparation program in fall 2009 were invited to participate in a study of their knowledge and classroom practices. These volunteers were all over 18 years of age and signed an informed consent.

Approximately one week prior to the training for the ADEPT assessment, co-researcher Dr. Janice Tucker attended a session of the EDTP 521: Literacy and Language in Diverse Classrooms course to invite teacher candidates to participate in this study. Dr. Tucker distributed the invitation letter and informed consent at this time. A link to Flashlight, an online survey program, including demographic questions was distributed to the volunteer teacher candidates to determine their knowledge of teaching practices prior to the training. Post surveys were conducted via Flashlight at the end of the fall 2009 semester. The Flashlight survey automatically assigned a code of random numbers to each participant to ensure confidentiality. Data from the survey were stored electronically on the researcher's computer in a locked file. Volunteers received the link to these Flashlight surveys and were able to complete them on their own time at a location of their choosing. 
During the second semester of student teaching in spring 2010 a smaller cohort was placed in a classroom situation where they were given an opportunity to apply the knowledge gained with the intended student population (ELLs). Interviews were conducted by co-researcher Dr. Tucker with this smaller sample to provide further information on the effectiveness of the ADEPT training as it applied to actual teaching practices. The interview questions were based on the questions contained in the Flashlight survey. Names of these teacher candidates were kept confidential. The interviews were recorded and labeled with a random number to ensure confidentiality of student responses. The tapes were kept in a locked drawer in the researcher's office and will be destroyed upon completion of the project.

\section{SAMPLE}

A Flashlight survey was used to collect demographic information as well as student responses to maintain anonymity. The confidential Flashlight survey identified the sample for this study of volunteer teacher candidates enrolled in CLU's EDTP 521 course in the fall of 2009.

\section{SETTING}

Teacher candidates were invited to volunteer for participation in this study by co-researcher, Dr. Tucker. Dr. Tucker is not an instructor for these teacher candidates. The ADEPT training took place during the EDTP 521 class at California Lutheran University by CRLP certified trainer Teresa Nunez. All surveys for this study were conducted anonymously online through CLU's flashlight survey system and data were saved in a secure file.

\section{DATA AND ANALYSIS}

\section{Quantitative}

A total of sixteen teacher candidates participated in both the pre and post survey for this study. The following tables present a graphic representation of the survey data from both the pre and post surveys, organized by question.

With the exception of one respondent who appears to have marked "strongly disagree" for every question on both the pre and post surveys, there was a significant increase in positive responses after receiving training in the ADEPT assessment. Responses to questions 9 and 10 are noteworthy. In response to the statement, "I feel adequately prepared to report individual progress in English proficiency to parents," $81 \%$ of respondents agreed or strongly agreed on the post survey, whereas only $29 \%$ had responded positively on the pre survey. Responses to the statement, "I have a good understanding of where my students are struggling with English proficiency" show an even greater change, with $94 \%$ responding with agree or strongly agree on the post survey, while only $24 \%$ responded positively on the pre survey.

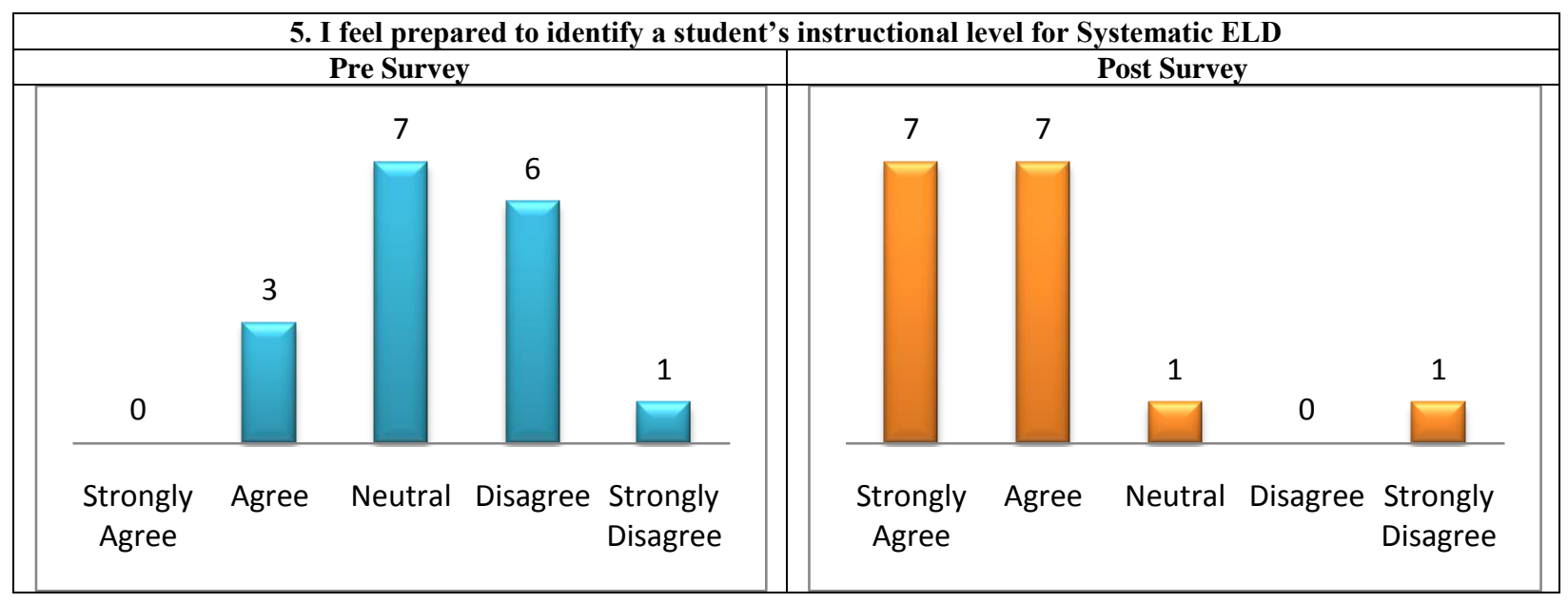




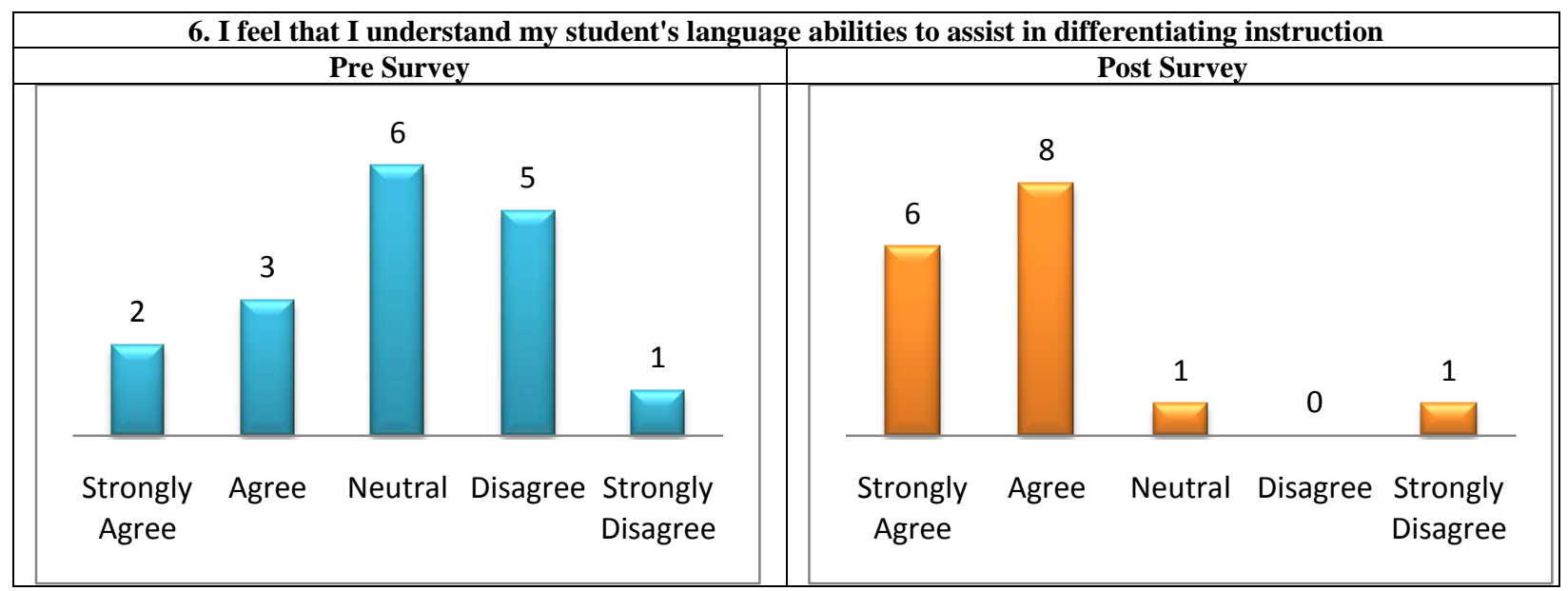

\begin{tabular}{|c|c|c|c|c|c|c|}
\hline \multicolumn{7}{|c|}{ 7. I am adequately monitoring student progress in English proficiency } \\
\hline \multicolumn{7}{|c|}{ Pre Survey } \\
\hline
\end{tabular}

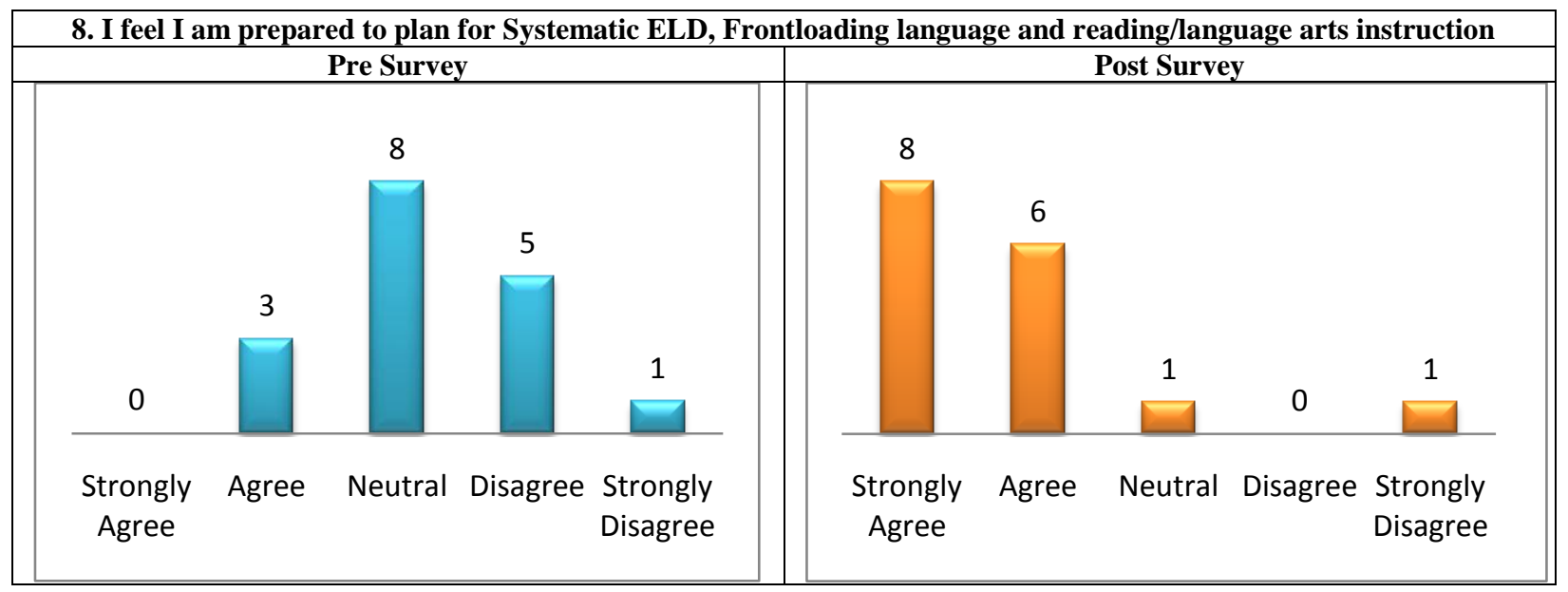



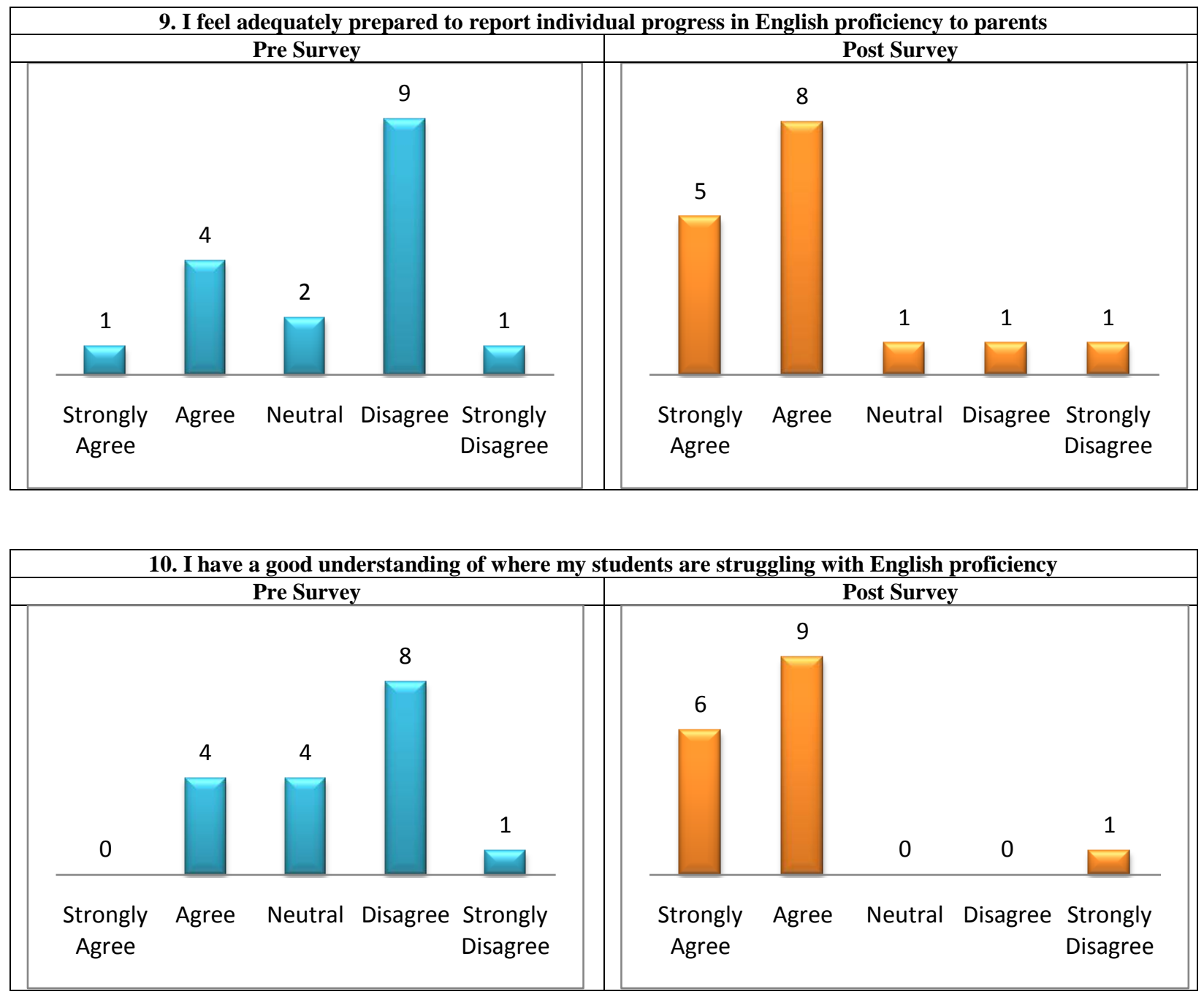

\begin{tabular}{|c|c|c|c|c|c|c|}
\hline \multicolumn{7}{|c|}{ 11. I am able to differentiate instruction based upon the assessment tools that are available to me } \\
\hline \multicolumn{3}{|c|}{ Pre Survey } & \\
\hline
\end{tabular}




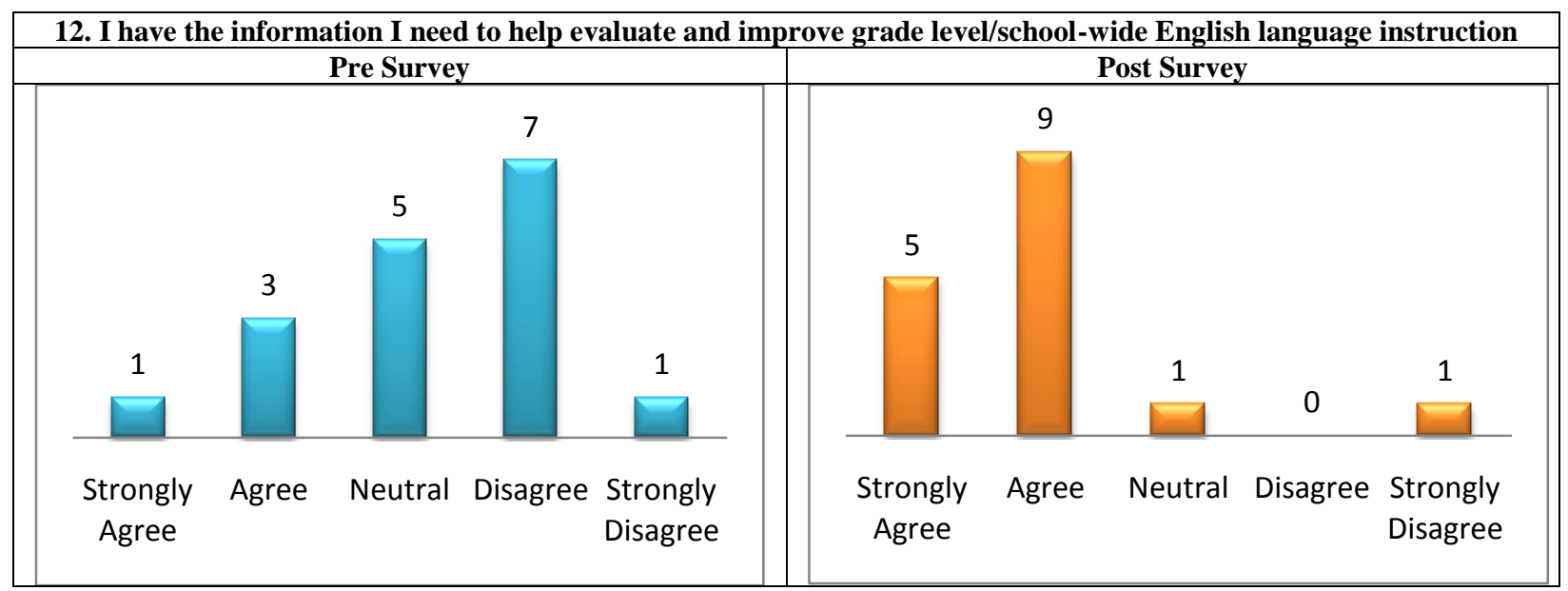

The responses for each question show an increase in confidence in preparing for and working with ELLs in the classroom. For every question in the post survey, there was an average of $87 \%$ response of agree or strongly agree, whereas the average for agree or strongly agree in the pre survey was only $29 \%$. Based on the survey data, it appears that the ADEPT assessment training was effective in assisting teacher candidates in determining a student's English language proficiency. This knowledge provides participants with a foundation for differentiating instruction and reporting progress to parents.

\section{Qualitative}

Data from the in depth interviews with teacher candidates the following semester confirmed and expanded upon the findings of the surveys given during the fall semester. Among the interviews, there was a strong theme of confidence in determining a student's language proficiency. The ability to determine language proficiency gained through administering the ADEPT, lead to a greater ability in differentiating instruction for ELLs. Furthermore, the ADEPT assessment helped teacher candidates to pinpoint exactly where a student was struggling with English. For example, one interviewee stated,

It gives you the level, but more specifically looking at the questions because I don't think there is one blanket instructional level... It breaks it down so you know which areas need the most work. I found that a lot of my kids needed help with reflexive words like yourself and themselves.

Another interviewee gave an interesting spin on the same idea, stating,

It's good to know what students actually know, rather than what they pretend to know. You really see that a lot in kindergarten... Even though they have no idea what they are doing, they look around to see what the other kids are doing. So the ADEPT was good to see what skills they really have.

Teacher candidates felt empowered and better equipped to serve the diverse populations in their classrooms after receiving training in the ADEPT assessment. The ADEPT was described as being "foundational" in determining where to start with instructional planning. One interviewee summed up the general consensus well in the following quote:

The [ADEPT] has given us the tools to be able to assess their needs and where their levels are as far as the English language and where we can help them. I'm not a Spanish speaking individual so I wouldn't know where to start. There is obviously the CELDT scores. But all my kids scored intermediate and they scored differently on this test. So this gave me all the different things that they need help with. It's just so explicit. 
Another interviewee was very explicit in sharing how the ADEPT was useful in his/her teaching experience, stating,

The ADEPT helps you pinpoint the problem. And then once you know the problem, it's a lot easier to determine how you are going to differentiate instruction. It's hard to differentiate when you don't know the needs. So it helps you find the needs.

Differentiating instruction is key to meeting ELLs where they are in terms of development and pushing them to the next level. Without knowing a student's strengths and weaknesses, it is hard to know where to start.

A final common thread among the interviews included the idea that the ADEPT gave concrete, reportable evidence about information that teachers already knew. One interviewee stated,

As a teacher you generally know your students but having the ADEPT and other strategies gives you concrete information that you can hand them and say "look, I did this with them. This is how they performed." And they will have something concrete to look at. Not just your opinions and what's happened in the classroom.

Measurable evidence is important, especially in this age of accountability for classroom teachers. Interviewees also commented on how the ADEPT gives teachers the opportunity to monitor their students' progress in English proficiency acquisition. When the ADEPT is given at the beginning and end of a school year, teachers know in what areas students have improved and where they are still struggling. This information can be given to the student's next teacher for follow up.

The teacher candidates who were interviewed also showed a general consensus of being uncomfortable with reporting student data to parents. However, this general discomfort did not seem to be tied to a lack of knowledge about where students were struggling or showing improvement, but rather seemed tied to the language barrier between the interviewee and the parents. The interviewees also shared the perspective that many parents of ELLs seem disinterested or too busy to be involved in monitoring their students' language proficiency. For the teacher candidates who were interviewed for this study, it seems that more exposure and experience is needed in this area rather than gaining more knowledge and information to report.

\section{DISCUSSION}

The data from this research study demonstrate that the ADEPT has played a key role in developing the confidence necessary to strategize and differentiate education for ELLs for this sample of pre-service teacher candidates. The knowledge gained from giving the ADEPT assessment to students appeared to give teacher candidates a solid foundation when developing lesson plans and determining how and when to differentiate instruction. It appears that the ADEPT assessment was effective in increasing teacher candidates' ability to plan instruction for ELLs. The ability to meet students where they are instructionally is integral to laying the foundation for academic success.

The ADEPT assessment provides teachers the opportunity to monitor progress toward English proficiency and give concrete evidence of improvement to parents and school administration. The information gained from giving the ADEPT was also useful in filling in the gaps left by the CELDT scores.

Overall, the ADEPT assessment appears to have met the research goal of this paper and was found to be a useful tool for teachers who are seeking to improve the educational experience of ELLs.

\section{LIMITATIONS AND FUTURE DIRECTIONS}

This study has the potential for the following limitations. Because teacher candidates are placed in elementary classrooms for only three mornings per week during their first semester of student teaching, the results may not provide an accurate representation of how the ADEPT assessment informs full-time instruction. Because there were only 22 teacher candidates enrolled in EDTP 521 in fall 2009 who could potentially participate in this 
study, the sample size is limited.

In order to truly pinpoint whether or not use of the ADEPT assessment was effective in improving ELLs' test scores, a study structured similarly to this one could be conducted using full time elementary teachers. These teachers could be given a pre and post survey related to their ability to meet the needs of ELLs, along with a follow up interview for more in-depth understanding. A sample of ELLs could be monitored for progress by being given a test at the beginning and end of the school year to check for improvement.

The limited sample size may not allow the research to transfer to a larger, more diverse population. This research could be conducted longitudinally with future semesters of teacher candidates. A larger sample size would increase the validity of the findings in this study.

\section{AUTHOR INFORMATION}

Nancy Myers has worked in the field of K-6 Public Education for over 27 years. During this time, she has served as a Reading Specialist, Literacy Coach, Multiple Subjects teacher, Literacy Presenter, Houghton-Mifflin consultant, California Reading \& Literature Project teacher leader, and California State Literacy Trainer. Nancy is also the Director for the California Reading and Literature Project. She is responsible for coordinating high quality professional development in the area of student literacy for teachers in public K-12 schools across Ventura, Santa Barbara, San Luis Obispo, and Kern County. This project works heavily with the English Language Learner population and focuses on improving low achieving schools.

Dr. Tucker teaches courses at CLU in the master's and doctoral programs in Educational Leadership that focus on educational policy, organizational change and leadership in the K-12 system. She brings experience as a classroom teacher and administrator in K-12 schools and as a curriculum consultant in elementary education. Dr. Tucker has taught at both Mount Saint Vincent University and Indiana University. Along with teaching and advising graduate students at CLU, Dr. Tucker coordinates the Professional Clear Administrative Services Credential Program.

\section{REFERENCES}

1. California Department of Education. (2009). 2008-2009 accountability progress reporting. Retrieved from http://ayp.cde.ca.gov/reports/AcntRpt2009/2009AYPco.aspx?cYear=\&cSelect=56,VENTURA\&cChoice= AYP2007

2. California Department of Education. (2010). Data quest: Number of English learners. Retrieved from http://dq.cde.ca.gov/dataquest/lc/NumberElCounty.asp?Level=County\&cCode=56\&cName=VENTURA\& TheYear $=2009-10$

3. Cummins, J. (1995). Empowering minority students: A framework for intervention. In O. Garcia (Ed.), Policy and practices in bilingual education (pp. 103-114). Clevedon, UK: Multilingual Matters.

4. Ed Data. (2010). Retrieved from http://www.eddata.k12.ca.us/Navigation/fsTwoPanel.asp?bottom=/profile.asp\%3Flevel\%3D05\%26reportNumber\%3D16

5. Gándara, P., Rumberger, R., Maxwell-Jolly, J. \& Callahan, R., (2003). English learners in California schools: Unequal resources, unequal outcomes. Education Policy Analysis Archives, 11(36). Retrieved August 29, 2010 from http://epaa.asu.edu/epaa/v11n36/

6. Garcia, G. G. (2005). Revisioning the blueprint: Building for the academic success of English language Learners. In G. G. Garcia (Ed.), English learners: Reaching the highest level of English literacy (pp. 197226). Upper Saddle River, NJ: Pearson/Merrill Prentice Hall.

7. Gonzalez, J., \& Darling-Hammond, L. (1997). New concepts for new challenges: Professional development for teachers of immigrant youth. McHenry, IL: Center for Applied Linguistics and Delta Systems.

8. Grant, R., \& Wong, S. (2003). Barriers to literacy for language minority learners: An argument for change in the literacy education profession. Journal of Adolescent and Adult Literacy, 46(5), 386-394.

9. Hakuta, K. (2000). How long does it take English learners to attain proficiency. Retrieved May 4, 2009 , from http://repositories.cdlib.org/lmri/pr/hakuta 
10. Lucas, T., Villegas, A.M., \& Freedson-Gonzalez, M. (2008). Linguistically responsive teacher education: Preparing classroom teachers to teach English language learners. Journal of Teacher Education, 59(4), 361-373. from Academic OneFile via Gale: http://find.galegroup.com.ezproxy.callutheran.edu/gtx/infomark.do?\&contentSet=IACDocuments \&type $=$ retrieve $\&$ tabID=T002\&prodId=AONE\&docId=A184538798\&source $=$ gale \&userGroup Name $=$ callutheran \&version $=1.0$

11. Olson, L. (2010). Reparable harm: Fulfilling the unkept promise of educational opportunity to California's long term English learners. Long Beach, CA: Californians Together.

12. Ruddell, R., \& Unrau, N. J. (1997). The role of responsive teaching in focusing reader attention and developing reader motivation. In J. Guthrie \& A. Wigfield (Eds.), Reading engagement: Motivating readers through integrated instruction. (pp. 954-978). Newark, DE: International Reading Association. 


\section{NOTES}

